\title{
Ameliorating effect of selenium nanoparticles on cyclophosphamide-induced hippocampal neurotoxicity in male rats: light, electron microscopic and immunohistochemical study
}

\author{
H.M. Ibrahim ${ }^{1}$ (D, M.A. Zommara², M.E. Elnaggar ${ }^{1}$ \\ ${ }^{1}$ Department of Anatomy and Embryology, Faculty of Medicine, Ain Shams University, Cairo, Egypt \\ ${ }^{2}$ Department of Dairy Science, Faculty of Agriculture, Kaferelshikh University, Kaferelshikh, Egypt
}

[Received: 3 September 2020; Accepted: 13 September 2020; Early publication date: 23 September 2020]

Background: Cyclophosphamide (CPH) is a widely used chemotherapeutic drug that can affect the hippocampal neurocytes with a subsequent effect on memory and cognitive functions. Nanomedicine has the potential to overcome the current chemotherapeutic side effects, because of the unique nanoscale size and distinctive bioeffects of nanomaterials. So, the present study aims to investigate the potential ameliorative effect of the biologically synthesized nano-selenium (nano-Se) on CPH induced hippocampal neurotoxicity.

Materials and methods: Twenty four rats were randomly classified into four groups of 6 rats each: control group, nano-Se group (dose of $0.5 \mathrm{mg}$ biological nano-Se/kg daily via oral gavage), CPH group (dose of $20 \mathrm{mg}$ CPH/kg daily intraperitoneally), and CPH plus nano-Se group. After 4 weeks, the rats were sacrificed and the hippocampus was excised and processed. Sections were stained with haematoxylin and eosin stain and immunohistochemically stained for caspase-3 (apoptosis marker) and glial fibrillary acidic protein (astrocytic activity marker) (GFAP). Morphometric analysis and transmission electron microscopic (TEM) examination were also done.

Results: Control and nano-Se groups revealed no structural changes. By light microscopy, CPH group showed degeneration and necrosis of hippocampal neurocytes, significantly reduced thickness of the neurocyte cell layers, increased expression of GFAP and caspase-3 immunostains and significantly elevated apoptotic index. Moreover, neurocytes damage, mitochondrial cristeolysis, mild dilation of rough endoplasmic reticulum, and disrupted neurolemmal sheaths of nerve fibres were also demonstrated by TEM. Nano-Se cotreatment in the fourth group reversed all the aforementioned deleterious changes that induced by $\mathrm{CPH}$ in the hippocampal neurocytes.

Conclusions: Treatment with $\mathrm{CPH}$ caused damage to hippocampal neurocytes that can be reversed by biological nano-Se co-treatment. (Folia Morphol 2021; 80, 4: 806-819)

Key words: cyclophosphamide, hippocampus, neurotoxicity, nano-selenium 


\section{INTRODUCTION}

Selenium ( $\mathrm{Se}$ ) is an indispensable trace element, needed for the maintenance of growth and health [47]. It plays a rule in illness prevention and fertility $[9,10]$. Recently, with the progress of the nanotechnology field, nano-selenium (nano-Se) has gained widespread attention because the nanoparticles exhibit innovative properties such as a powerful adsorbing capacity, high surface activity, high catalytic ability, and less toxicity [46]. Some studies have also pointed out the possibility of use of nano-Se in the field of medical treatment as antimicrobial, anti-biofilm [45] and anticancer [57].

Nano-Se can be synthesized by chemical and biological methods. In chemical methods, the chemical stabilizers used may lead to environmental pollution [15]. On the contrary, biological synthesis is preferred as it is a nontoxic, clean, cost-effective, and more accessible approach. Moreover, nanoparticles produced by the biological methods have more novel properties $[19,36]$. There are relatively few reports on the biologically synthesized nano-Se and it is still a big challenge for researchers to elucidate the potential health benefits of nano-Se [24].

Cyclophosphamide (CPH) is an anticancer agent, which is ordinarily used to treat numerous types of cancer [37]. Administration of $\mathrm{CPH}$ triggers oxidative stress in the brain [25] and massive cellular degeneration [39], consequently provoking apoptosis [32], and damage to cancer and healthy cells [49]. CPH uptake into healthy cells is higher than in cancer cells, rendering healthy cells more susceptible to damage [8]. The antineoplastic effects of $\mathrm{CPH}$ are associated with the production of acrolein which is the cause of the toxic side effects of CPH [28]. Acrolein diminishes cellular defence against oxidative stress, which can corrupt the blood-brain barrier $[3,50]$. Moreover, CPH can alkylate DNA, inhibits the duplication of the genome in dividing cells, and arrests the cell cycle particularly at the S-phase $[6,51]$.

Treatment with $\mathrm{CPH}$ induces cognitive and psychological impairments especially the hippocampal-dependent memory task due to the negative impact of $\mathrm{CPH}$ on hippocampal neurogenesis [23, 43]. Neurogenesis continues in the hippocampus throughout adulthood [23]. The neurotoxic effects of $\mathrm{CPH}$ include not only neuronal damage but also disruption of the cholinergic pathways [2]. The aforementioned reports point out that there is a necessity to explore the possible therapeutic approaches to mitigate the neurotoxicity induced by cyclophosphamide on hip-

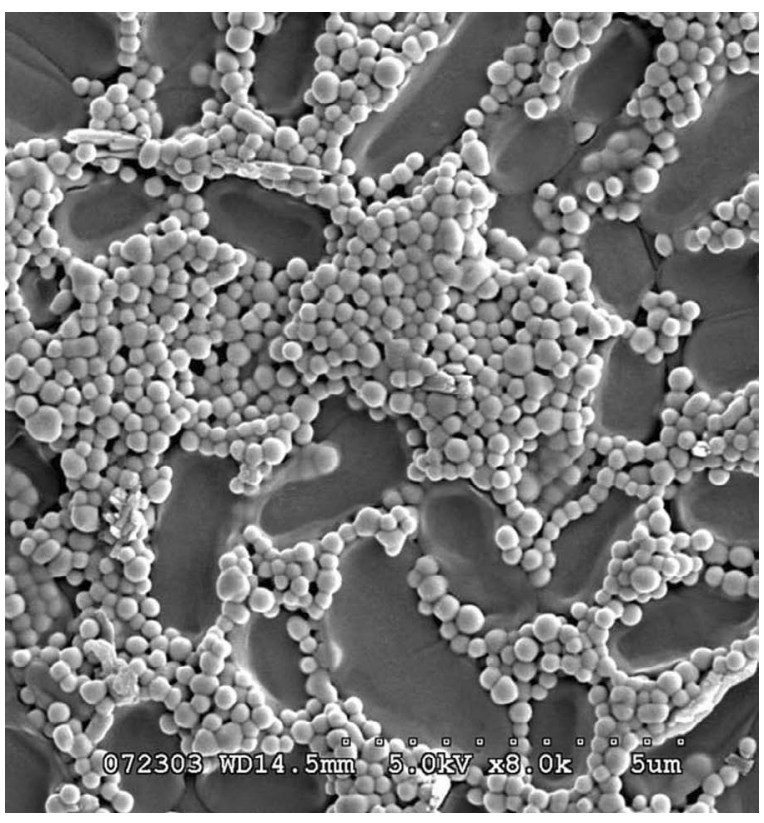

Figure 1. Scanning electron microscopic photograph of a yoghurt culture-nano-selenium suspension.

pocampal neurons. Therefore, the present study was conducted to investigate the potential ameliorative effect of the biologically synthesized nano-Se on CPH induced hippocampal neurotoxicity.

\section{MATERIALS AND METHODS}

\section{Drugs}

Cyclophosphamide (CPH). Cyclophosphamide monohydrate, trade name Endoxan, was manufactured by Baxter Oncology GmbH (Kantstrasse, Germany). It was available in the form of vials. Each vial contained $1 \mathrm{~g}$ CPH (dry powder). CPH was dissolved in saline to be intraperitoneally injected in rats.

Selenium nano-particles (nano-Se). Biologically synthesized nano-Se was prepared using yoghurt culture (Lactobacillus delbrueckii subsp. bulgaricus [L. bulgaricus, NCAIM B 02206] and Streptococcus thermophilus [S. thermophiles, CNCM I-1670] cultivated in MRS medium as described by Prokisch and Zommara, 2010 [41]. Nano-Se size ranged from 55 to $238 \mathrm{~nm}$ with an average of $122.6 \pm 34.6$ (SD) or $122.6 \pm 8.6$ (SE). Scanning electron microscopic (JSMIT100, JEOL Co. Japan) photos of purified nano-Se were used for nano-Se size determination according to Nagy et al. [35] 2016 (Fig. 1).

\section{Animals}

Twenty four adult male albino rats with an average weight of 200-250 $\mathrm{g}$ were used in the current exper- 
imental study. The animals were treated according to the guidelines of the Committee of Animal Research Ethics of the faculty of medicine, Ain-Shams University. The animals were housed in a convenient environment; 6 rats per cage, food, and water were freely allowed. All rats were exposed to 12 hours light-dark cycle, good ventilation, and suitable temperature $22-25^{\circ} \mathrm{C}$.

\section{Experimental design}

Animals were divided into four groups:

- group I (control group): 6 rats received $0.1 \mathrm{~mL}$ of a saline intraperitoneal injection daily for 4 weeks;

- group II (nano-Se group): 6 rats received nano-Se $(0.5 \mathrm{mg} / \mathrm{kg}$ body weight) by oral gavage daily for 4 weeks [16];

- group III (CPH group): 6 rats received a $\mathrm{CPH}$ (20 mg/kg body weight) intraperitoneal injection daily for 4 weeks [34];

- group IV (CPH plus nano-Se group): 6 rats received a CPH (20 mg/kg body weight) intraperitoneal injection daily and nano-Se $(0.5 \mathrm{mg} / \mathrm{kg}$ body weight) by oral gavage daily for 4 weeks.

\section{Light microscopic studies}

At the end of the 4 weeks experimental period, rats were anaesthetised by ether, and then sacrificed also with a fatal dose of ether. For each animal, the brain was extracted. The cerebral hemispheres were separated into right and left halves. Then, the posterior portion of the brain containing the hippocampus was cut. The right hippocampus was put in $10 \%$ formal saline ( 5 days). Specimens were then dehydrated, cleared, and embedded in paraffin. Sagittal sections $(5-\mu \mathrm{m})$ were cut and stained with haematoxylin and eosin (H\&E) [4], and immunohistochemical staining for caspase-3 (apoptotic marker) and glial fibrillary acidic protein (GFAP) were also performed. GFAP was utilized to investigate the astrocytes distribution and their response to neurocyte damage [31].

\section{Immunohistochemical staining}

Tissue sections were deparaffinised, rehydrated and $10 \%$ hydrogen peroxide was added for endogenous peroxidase inhibition. Then, boiling with citrate buffer $\mathrm{pH}$ 6.0. For antigen retrieval was done. Sections were also incubated with the primary antibodies: anti-caspase-3 (BIOCYC GmbH, Germany), and anti-GFAP (Goat Polyclonal IgG, anti-rat antibody; Dako Cytomation, USA). Subsequently, incubation with the secondary antibody, a biotinylated goat anti-rabbit immunoglobulin and a streptavidin-biotin complex was done. The site of the reaction was visualised by adding diaminobenzidine $\mathrm{HCl}$, which was converted into a brown precipitate by peroxidase. Finally, haematoxylin was utilised for counterstaining [5].

\section{Transmission electron microscopy}

The left hippocampal formation was extracted immediately after sacrificing the animals; samples were cut into small pieces $(1 \times 1 \times 1 \mathrm{~mm})$. The pieces were thereafter fixed in formal glutaraldehyde $2.5 \%$ for 2 days. Then, postfixation with a $1 \%$ osmium tetroxide solution was performed. Washing four times with phosphate buffered saline and dehydration through graded ethanol was done followed by clearing in propylene. Finally, the specimens were embedded in epoxy resin. Semithin sections were cut $(1 \mu \mathrm{m})$ and stained with toluidine blue and inspected by light microscope. Then, cutting the ultrathin sections $(60 \mathrm{~nm})$ and staining with uranyl acetate and lead citrate was done. The sections were examined using a transmission electron microscope (TEM) (Jeol 1200Ex, Japan) at the Electron Microscopy Centre, Faculty of Science Ain Shams University, Cairo, Egypt [42].

\section{Morphometric and statistical analysis}

The following data were measured:

- the thickness of the neurocyte cell layer, i.e. the pyramidal cell layer in CA1 and CA3 zones and the granular cell layer in dentate gyrus (DG). Vertical lines were drawn, by the software (Image Pro-Plus), from the uppermost pyramidal cell (or granule cell) to the lower most one detected. The lines were then measured;

- the area percentage of GFAP reaction, and the number of GFAP positive cells in CA1 in all groups. Briefly, the GFAP positive cells were marked by the software and the area percentage and the number of cells were counted at the high-power field ( $\times 400$ magnification);

- the area percentage of caspase- 3 reaction in CA1 in all groups. The caspase- 3 positive cells were marked by the software and the area percentage was counted at the high-power field ( $\times 400$ magnification). The number of caspase-3 positive cells (apoptotic cells) was expressed frequently in the previous studies by the apoptotic index (AI) [55]. 

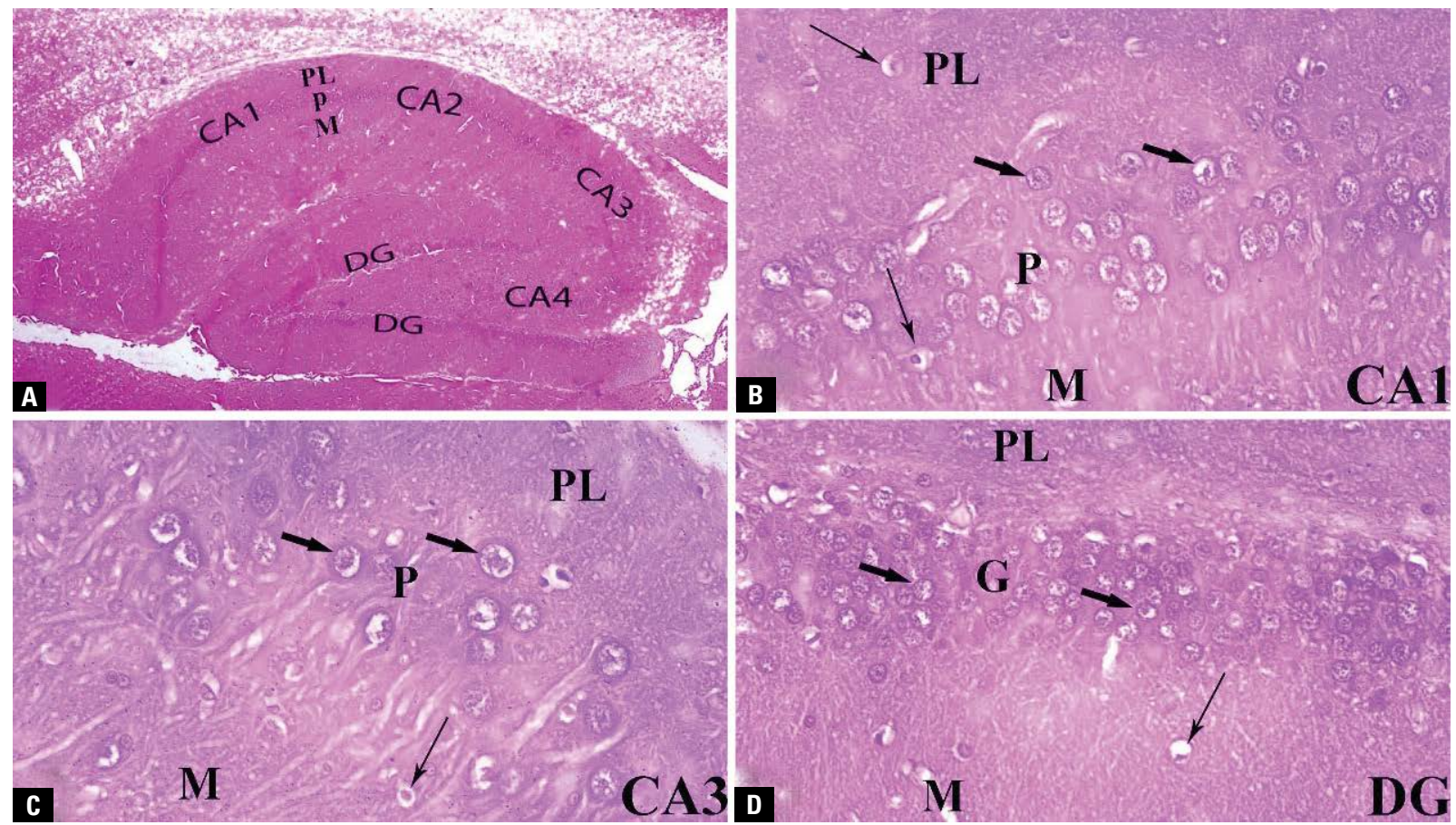

Figure 2. A. Hippocampus of control rat showing the dentate gyrus (DG) and the four regions of hippocampus CA1, CA2, CA3, and CA4; B-D. Showing that CA1, CA3 and DG are formed of 3 layers; PL — polymorphic layer; $\mathrm{p}$ - pyramidal cell layer, $\mathrm{M}$ - molecular cell layer. The pyramidal cell layer is replaced by granule cell layer $(G)$ in DG. The thick arrows point to the pyramidal and granule cells and the thin arrows for the interneurons (H\&E stain; $A: \times 40 ; B, C, D: \times 400)$.

Five different captures in non-overlapping high-power fields $(\times 400)$ were taken in the slides of each rat in all groups (the H\&E stained slides and the immunostained slides). Then, the aforementioned parameters were measured by software. The Al represented the percentage of apoptotic cells in 1000 cells. Meanwhile, the Al was determined by counting at least 1000 cells per slide, subdivided into 10 fields chosen randomly. The counting process was done at $400 \times$ magnification. $\mathrm{Al}=$ (number of caspase-3 positive cells/total number of calculated cells) $\times 100$. Measurements were performed by an independent observer blinded to the specimens' details to achieve an unbiased evaluation. The morphometric analysis was performed on digital light microscopic images that had been captured by a digital camera Olympus (DP 20) on Olympus BX51 light microscope (Olympus, Hamburg, Germany). Image analysis procedures were carried out using the Image Pro-Plus Programme, Media cybernetics. Inc. (version 4.5.1.27).

All data were expressed as mean \pm standard deviation and statistically analysed by IBM SPSS Statistics version 20 using one-way AVOVA analysis of variance, followed by Tukey test to compare statistical differences between all groups at $p<0.05$.

\section{Ethics approval and consent to participate}

All the procedures of the experiment were carried out according to the guide rules of the Committee of the Animal Research Ethics, Faculty of Medicine, Ain Shams University.

\section{RESULTS}

\section{Light microscopic results}

Group (I and II: control and nano-Se groups). The microscopic sections of the control and nano-Se groups were nearly similar. In both groups, examination of H\&E stained sections of the hippocampus revealed that it was formed of the hippocampal proper (proprius) and the DG. The hippocampus proper was composed of four zones (CA1, CA2, CA3, and CA4) of cornu ammonis. CA1 and CA2 were located dorsally while CA3 made the descending arch that ended at the beginning of the hilus of the DG. CA4 is situated inside the hilus of the DG. The DG appeared as a dark V-shaped structure, with its open part encircling the CA4 area of the hippocampus. Each area was formed of 3 layers: polymorphic, pyramidal, and molecular (Fig. 2A). The molecular and polymorphic layers contained few neurocytes (nerve cells), whereas the pyramidal layer was formed of numerous neurocytes 

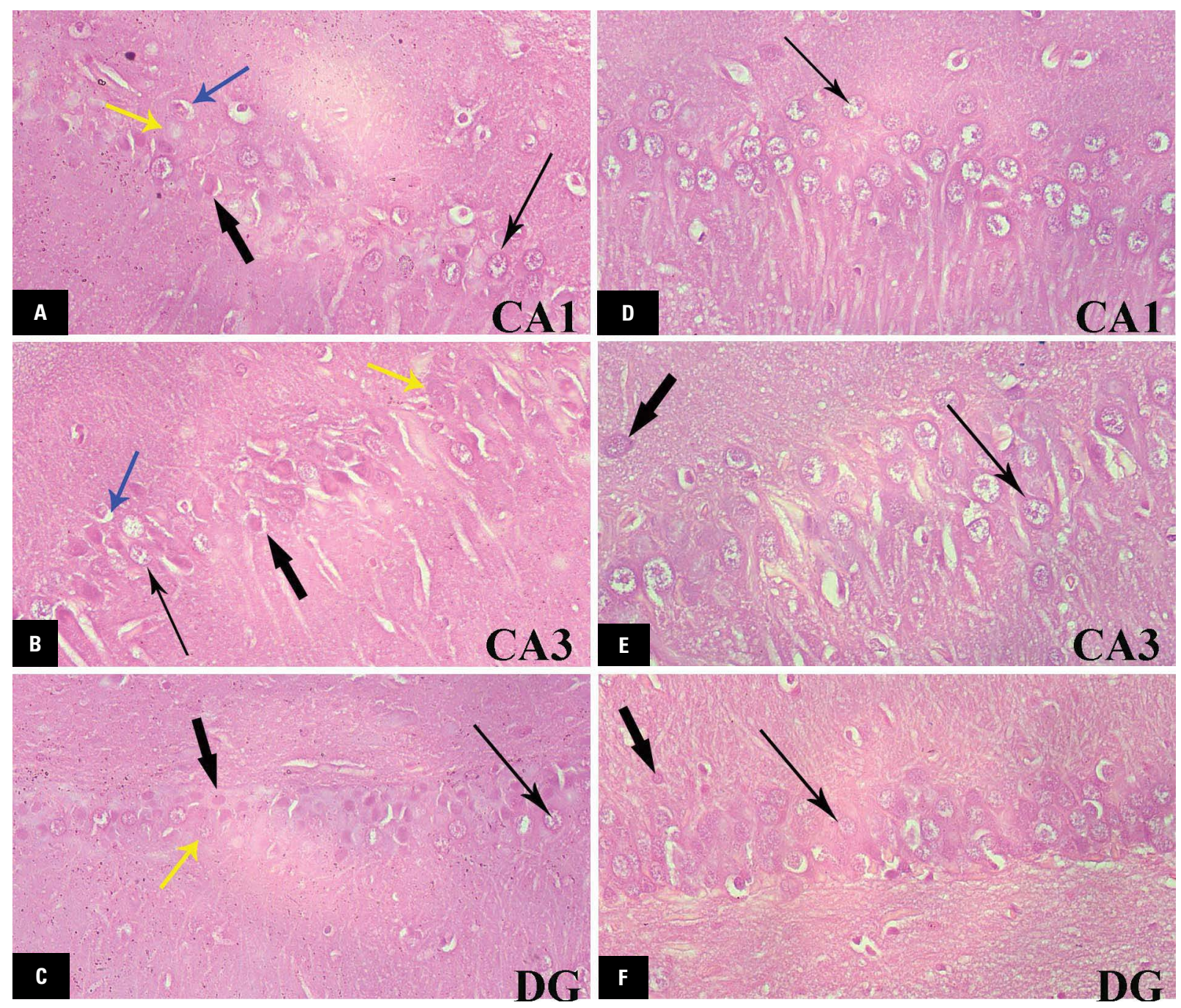

Figure 3. A-C. Sections from cyclophosphamide group showing the necrotic and degenerated neurocytes in all zones separated by few healthy cells; D-F. Sections in cyclophosphamide plus nano-selenium group showing that most of the neurocytes are healthy. Thick arrow — necrotic cell, thin arrow - healthy cell, yellow arrow — ghost like cell, blue arrow — cytoplasmic vacuolation in a degenerated cell $(H \& E$ stain $\times 400)$; DG — dentate gyrus.

(pyramidal cells) containing large vesicular nuclei with prominent nucleoli and pale basophilic cytoplasm. Glial cell interneurons were seen in all layers of the hippocampus. They had dark basophilic cytoplasm and deeply stained small rounded nuclei. The middle layer in the DG is called the granule cell layer instead of the pyramidal cell layer (Fig. 2B-D). The cellular structure of the various zones of the hippocampus proper is similar so figures of CA1 and CA3 were only included in the present study as examples to the different layers and to avoid repetition of unnecessary similar figures.

Group (III: CPH group). Hippocampus proper: The thickness of the pyramidal cell layer was apparently decreased. The pyramidal cells were disorganised and appeared either degenerated or necrotic. The cytoplasm of the degenerated cells was vacuolated with loss of cellular characteristics. The necrotic cells had shrunken deeply stained nuclei, i.e. pyknotic nuclei. Small perineural spaces were seen surrounding the necrotic pyramidal cells. Additionally, some cells had swollen karyolitic pale stained nuclei with pale faint cytoplasm giving the ghost-like appearance. Few cells were still healthy with vesicular nuclei in between the damaged cells (Figs. 3A, B).

Dentate gyrus: The granule cell layer was diminished in thickness and the majority of its cells had deeply stained shrunken pyknotic nuclei or ghost-like nuclei (Fig. 3C).

Morphometrically, the thickness of the pyramidal cell layer and the granule cell layer (neurocyte cell layers) was significantly decreased as compared to the 
Table 1. Thickness of the pyramidal cell layer in CA1 and CA3 and the granular cell layer in dentate gyrus of the hippocampus in different groups (in $\mu \mathrm{M}$ )

\begin{tabular}{lcccc}
\hline & Control & Nano-Se & CPH & CPH + nano-Se \\
\hline CA1 & $84.28 \pm 7.41$ & $87.48 \pm 7.75$ & $40.26 \pm 4.11^{\mathrm{a}}$ & $76.94 \pm 7.18^{\mathrm{b}}$ \\
CA3 & $112.34 \pm 5.50$ & $116.56 \pm 6.27$ & $57.97 \pm 5.46^{\mathrm{a}}$ & $107.06 \pm 8.00^{\mathrm{b}}$ \\
Dentate gyrus & $69.61 \pm 4.67$ & $71.92 \pm 4.06$ & $40.31 \pm 3.70^{\mathrm{a}}$ & $63.91 \pm 6.95^{\mathrm{b}}$ \\
\hline
\end{tabular}

Values are expressed as mean \pm standard deviation. $\mathrm{N}=6$ for each group. One-way ANOVA; asignificant vs. the control group; ${ }^{b}$ significant vs. the $\mathrm{CPH}$ group; $\mathrm{p}<0.05$ was considered significant. CPH — cyclophosphamide; nano-Se — nano-selenium

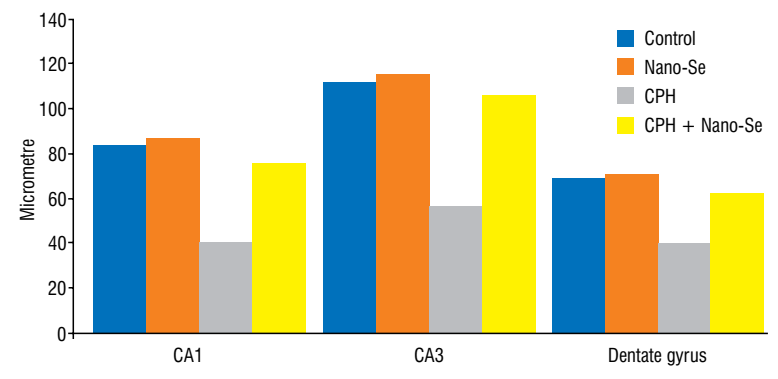

Figure 4. A histogram comparing the neurocyte cell layer thickness of the different groups; $\mathrm{CPH}$ - cyclophosphamide; nano-Se - nano-selenium.

control group $(p<0.05)$. So, the morphometric data were in harmony with the morphological observations (Table 1, Fig. 4).
Group (IV: CPH plus nano-Se group). Examination of H\&E-stained sections in the hippocampus of rats treated with CPH plus nano-Se revealed that most of the pyramidal cells and granule cells appeared healthy with large rounded or oval vesicular nuclei. Few cells with shrunken pyknotic nuclei with dark cytoplasm could be also seen in between the healthy cells (Fig. 3D-F). The thickness of the pyramidal cell layer and the granule cell layer was significantly elevated as compared to $\mathrm{CPH}$ group by morphometric analysis (Table 1, Fig. 4).

\section{Immunohistochemical results}

Immunohistochemistry for GFAP. The control group and the nano-Se group (I and II groups) showed few positive brownish star-shaped GFAP immunoreactive cells. The immunoreactive cells were large
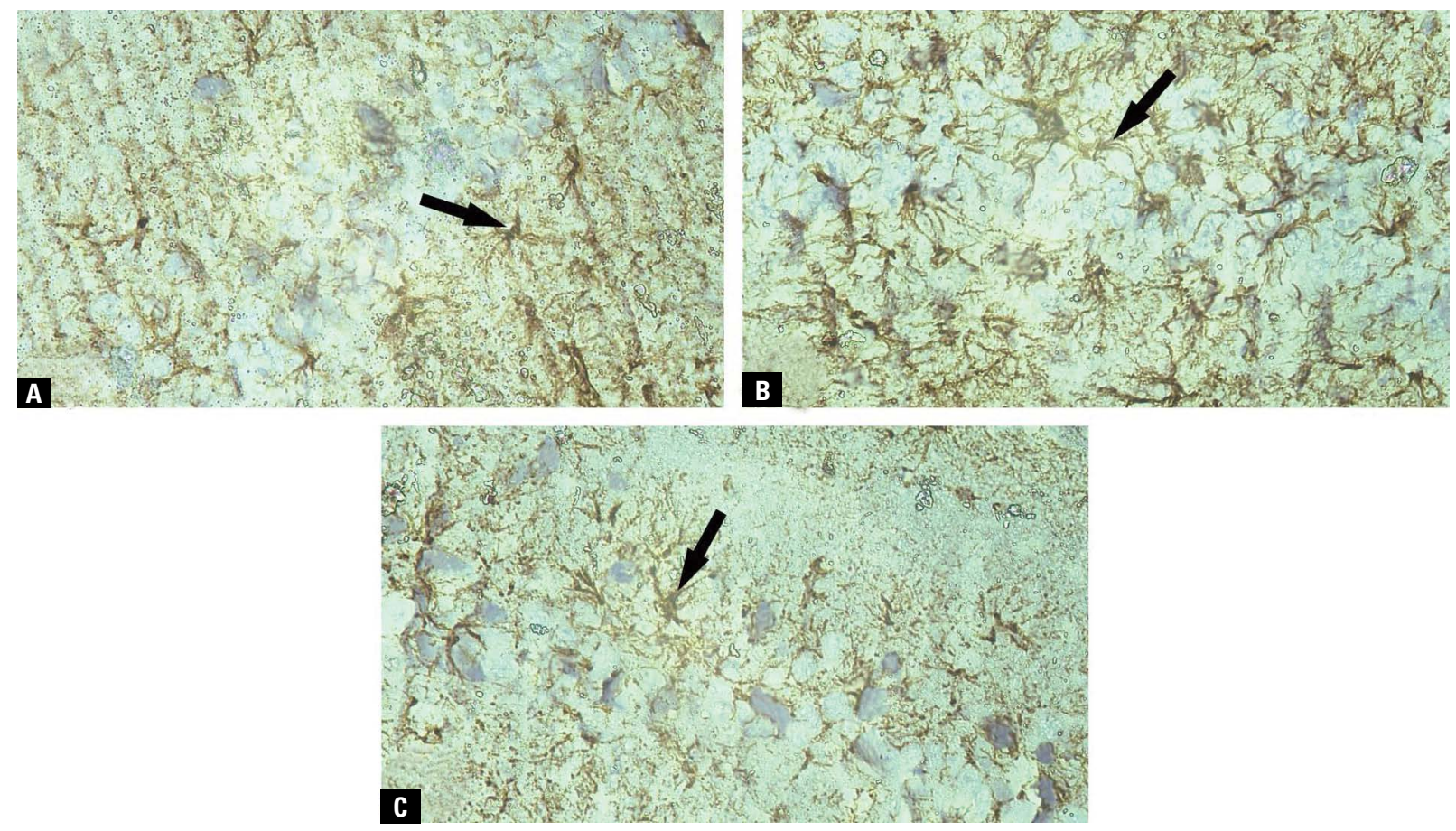

Figure 5. Sections in CA1; A. Few cells with positive reaction to glial fibrillary acidic protein (GFAP) in the control group; B. Many cells with positive reaction in cyclophosphamide (CPH) group; $\mathbf{C}$. Few cells with positive reaction in CPH plus nano-selenium group (GFAP immune-stain $\times 400)$. 
Table 2. The mean glial fibrillary acidic protein (GFAP) area percentage, number of GFAP positive cells, caspase-3 area percentage $(\%)$, and the apoptotic index (AI) in different groups

\begin{tabular}{lcccc}
\hline Groups & GFAP area $\%$ & Number of GFAP positive cells & Caspase-3 area \% & Al \\
\hline Control & $2.99 \pm 1.57$ & $2.73 \pm 1.44$ & $1.44 \pm 0.85$ & $0.43 \pm 0.25$ \\
Nano-Se & $2.24 \pm 1.53$ & $1.73 \pm 1.23$ & $1.24 \pm 0.92$ & $0.32 \pm 0.15$ \\
CPH & $18.56 \pm 10.25^{\mathrm{a}}$ & $19.23 \pm 6.60^{\mathrm{a}}$ & $15.06 \pm 6.12^{\mathrm{a}}$ & $33.66 \pm 5.14^{\mathrm{a}}$ \\
$\mathrm{CPH}+$ nano-Se & $7.07 \pm 2.96^{\mathrm{b}}$ & $5.47 \pm 2.11^{\mathrm{b}}$ & $5.73 \pm 1.61^{\mathrm{b}}$ & $10.54 \pm 2.58^{\mathrm{b}}$ \\
\hline
\end{tabular}

Values are expressed as mean \pm standard deviation. $\mathrm{N}=6$ for each group. One-way ANOVA; asignificant vs. the control group; ${ }^{b}$ significant vs. the CPH group; $\mathrm{p}<0.05$ was considered significant. CPH — cyclophosphamide; nano-Se — nano-selenium
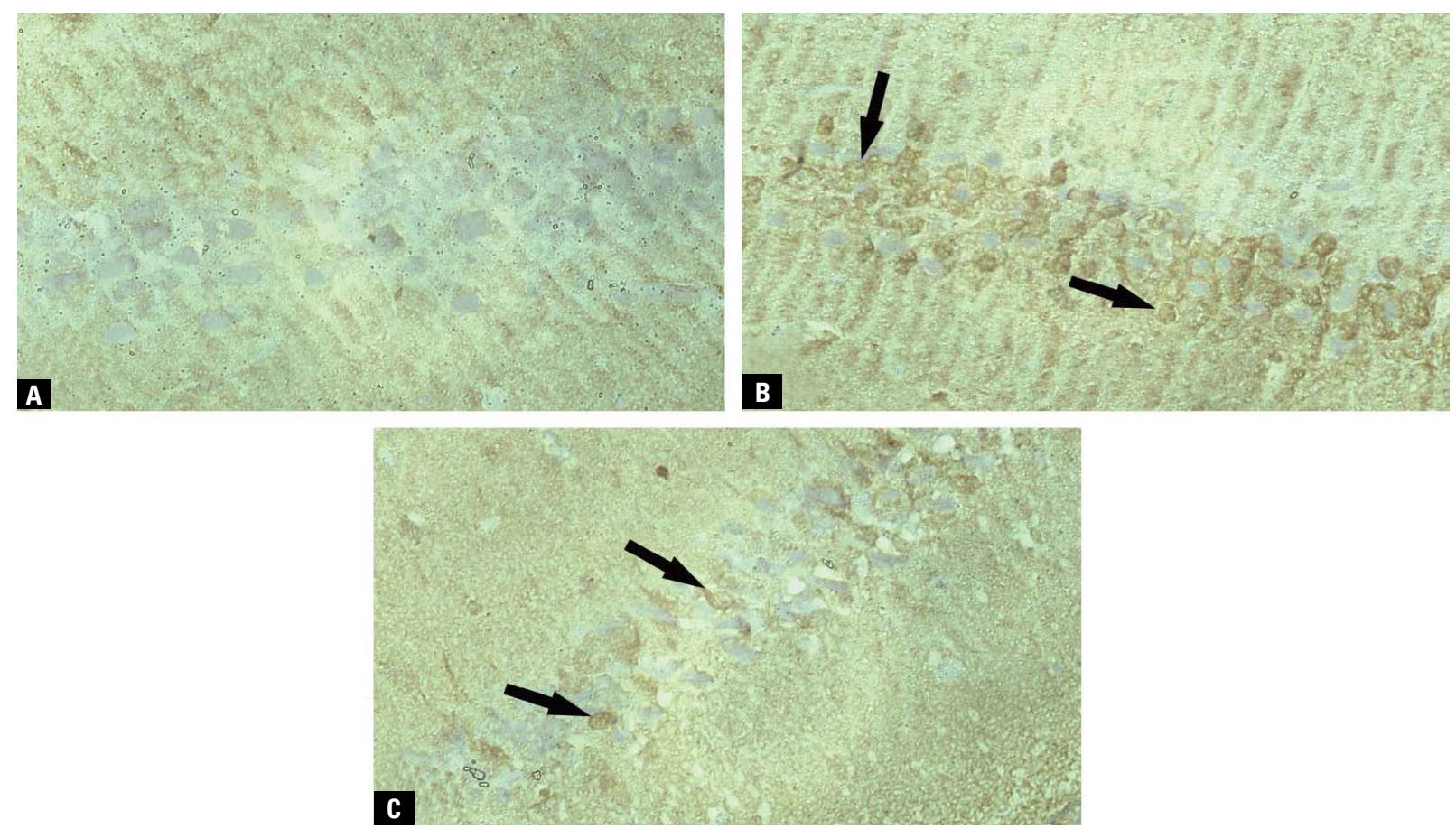

Figure 6. Sections in CA1; A. No positive reaction to caspase-3 in the control group; B. Many cells with positive reaction in cyclophosphamide (CPH) group; C. Few cells with positive reaction in CPH plus nano-selenium group (caspase- 3 immune-stain $\times 400$ ).

branched cells dispersed among various cell layers of the hippocampus. They were most probably activated astrocytes (Fig. 5A). The CPH group (group III) showed an apparent increase in the number and size of the star-shaped GFAP immunoreactive cells (Fig. 5B). The $\mathrm{CPH}$ plus nano-Se group (group IV) showed less number and size of the GFAP immunoreactive cells compared to the group of CPH treated rats (Fig. 5C). Morphometrically, the area percentage of the GFAP reaction and the mean number of immunoreactive cells were significantly increased in the $\mathrm{CPH}$ group as compared to the control group. Meanwhile, these measured parameters were significantly reduced in $\mathrm{CPH}$ plus nano-Se group as compared to the $\mathrm{CPH}$ group (Table 2, Fig. 7A).
Immunohistochemistry for caspase-3. Caspase-3 was rarely expressed in the neurocytes of the control and nano-Se groups (group I and II) (Fig. 6A). Enhanced staining of caspase-3 was observed in the neurocytes of the CPH group (group III) compared with the control group, indicating increased apoptosis (Fig. 6B). The CPH plus nano-Se group (group IV) showed decreased staining in comparison with the CPH group (Fig. 6C). Morphometrically, the area percentage of caspase- 3 reaction, and the Al were significantly increased in the $\mathrm{CPH}$ group compared to the control group. Meanwhile, these measured parameters were significantly decreased in $\mathrm{CPH}$ plus nano-Se group as compared to the $\mathrm{CPH}$ group (Table 2, Fig. 7B). 

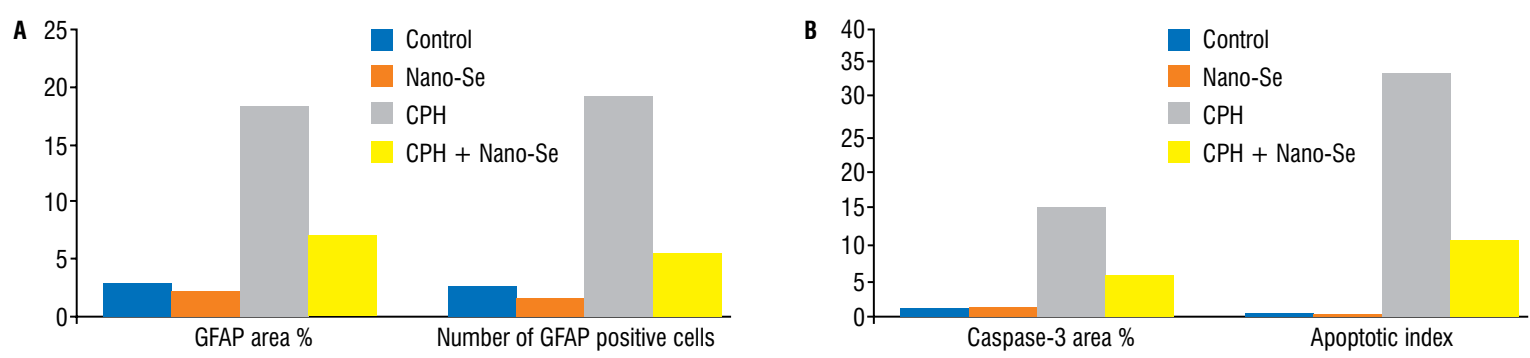

Figure 7. A histogram comparing; A. Glial fibrillary acidic protein (GFAP) area percentage and number of GFAP positive cells in the different groups; B. Caspase-3 area percentage and apoptotic index in the different groups; $\mathrm{CPH}$ - cyclophosphamide; nano-Se — nano-selenium.

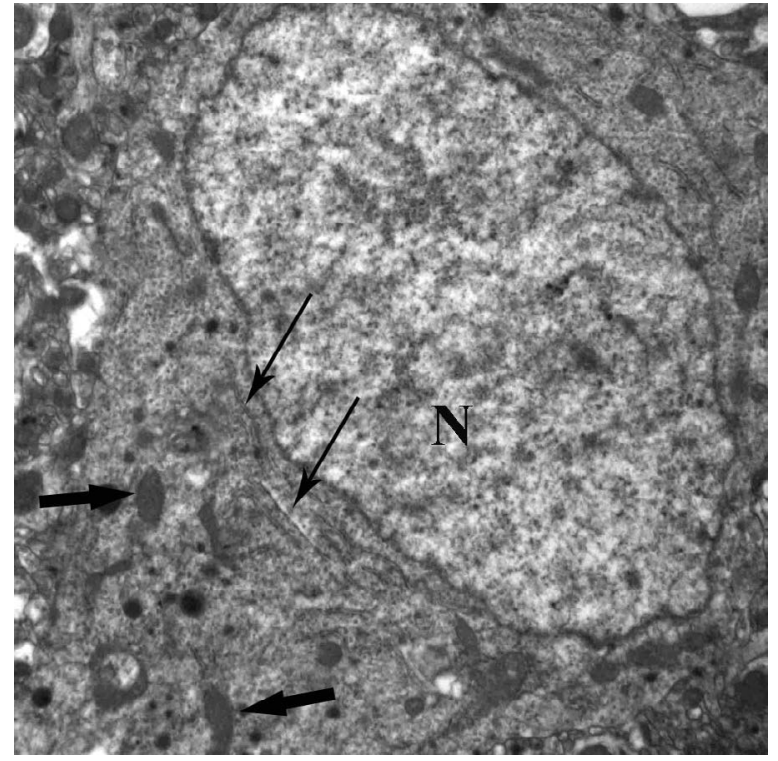

Figure 8. Transmission electron microscopic micrograph of a control neurocyte showing a large oval euchromatic nucleus (N), cisternae of rough endoplasmic reticulum (thin arrow), and intact mitochondria (thick arrow) $(\times 2500)$.

\section{Transmission electron microscopic (TEM) results}

Group (I and II: control and nano-Se groups). The neurocytes (nerve cells) of the control group showed large oval or rounded euchromatic nucleus with dispersed chromatin and a regular nuclear membrane. The cytoplasm contained multiple cisternae of rough endoplasmic reticulum, several free ribosomes, and intact mitochondria with prominent cristae (Fig. 8).

Group (III: CPH group). The nuclei of many cells had irregular outlines and condensed chromatin and some of them appeared shrunken and deeply stained, i.e. pyknotic (Fig. 9A, C). The nuclei of the degenerated cells appeared electro-lucent but their cytoplasm showed large vacuolation with remnants of the degenerated organelles (Fig. 9B). The mitochondrial cristae appeared damaged, i.e. cristeolysis and the cisternae of the rough endoplasmic reticulum were slightly dilated (Fig. 9D). Some neurolemmal sheaths of the nerve fibres were disrupted (Fig. 9A, C).

Group (IV: CPH plus nano-Se group). The majority of cells had electro-lucent nuclei with nearly regular outlines and dispersed chromatin and their cytoplasm showed healthy mitochondria and a nearly normal rough endoplasmic reticulum. The neurolemmal sheaths of the nerve fibres appeared intact (Fig. 10A, B). Some cells had normal cytoplasmic organelles and electro-lucent chromatin, but their nuclei still had irregular outlines (Fig. 10C). While most of the cells appeared healthy, few cells still had deeply stained nuclei and/or cytoplasmic vacuolation (Fig. 10D).

\section{DISCUSSION}

Chemotherapeutic drugs as cyclophosphamide have been a cornerstone of cancer therapy. Extensive effort was done on the synthesis of more efficient and less toxic chemotherapeutic drugs, but less attention has been paid to factors that may decrease the harmful side effects created by the antineoplastic agents. Moreover, the clinical outcome of treatment with these agents is critically restricted, frequently due to their toxicity to normal tissues. Consequently, there was a need to develop adjuvant treatment to enhance the effectiveness and/or diminish the associated side effects. Nanoparticles have the potential to overcome the obstacles in the treatment of cancer by the traditional antineoplastic agents, due to the unique nano size and novel characteristics of nanomaterials $[27,59]$.

In the current study, H\&E stained sections of the group of rats exposed to $\mathrm{CPH}$ showed either degeneration or necrosis of the neurocytes of the hippocampus, i.e. the pyramidal cells of the hippocampus proper and granule cells of the dentate 

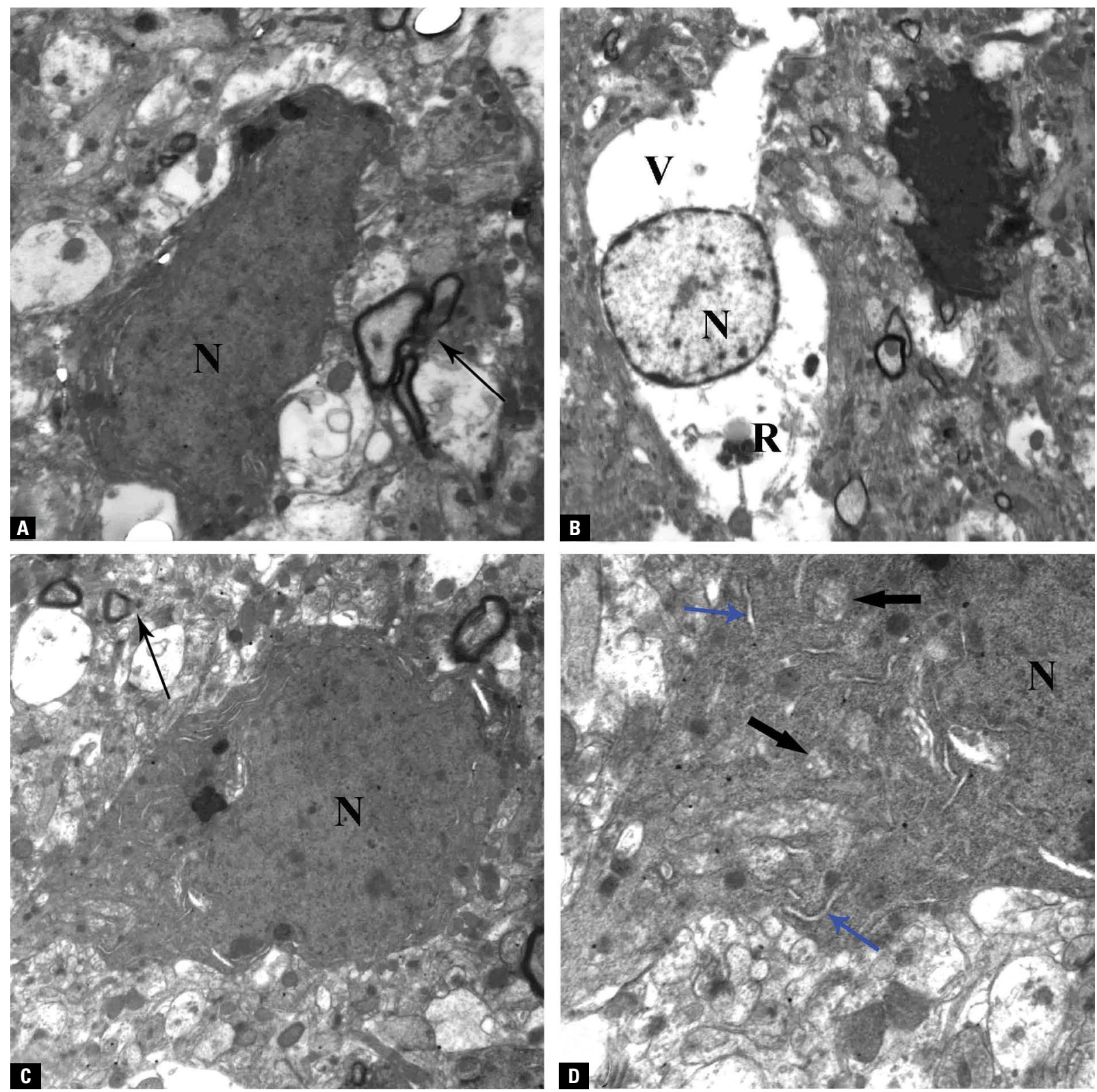

Figure 9. Transmission electron microscopic micrographs of neurocytes of the cyclophosphamide group; A. A nucleus (N) with irregular outline and condensed chromatin; B. A degenerated cell with electro lucent nucleus (N), vacuolated cytoplasm (V), and remnants of the degenerated organelles (R); C. A necrotic cell with a pyknotic nucleus (N); D. A higher magnification of panel C showing the cristeolysis of mitochondria (thick arrow) and the slightly dilated cisternae the rough endoplasmic reticulum (blue arrow). The disrupted neurolemmal sheaths (thin arrow) are seen in panels $A$ and $C(A, C: \times 2500, B: \times 1500, D: \times 6000)$.

gyrus. The thickness of the pyramidal and granule cell layers was also significantly reduced. The results of the current study were similar to the observations of Shaibah et al., 2016 [44] who postulated that CPH caused highly significant dystrophic and apoptotic alterations in the neurocytes of the hippocampus with a marked reduction in the neurocyte cell layer thickness. On the contrary, Lyons et al., 2011 [30] pointed out that CPH did not affect the survival of the cells of the hippocampus in rats after a short-term treatment and it is less neurotoxic than other antineoplastic agents. Consequently, it is concluded that $\mathrm{CPH}$ could provoke neuronal damage in the hippocampus due to the long term and not in short term treatment.

The H\&E stained sections of the rats treated with $\mathrm{CPH}$ plus nano-Se, in the present study, showed that most of the neurocytes were healthy in the hippocampus apart from few cells exhibited dystrophic changes. Additionally, the thickness of the pyramidal cell layer and granule cell layer was significantly increased 

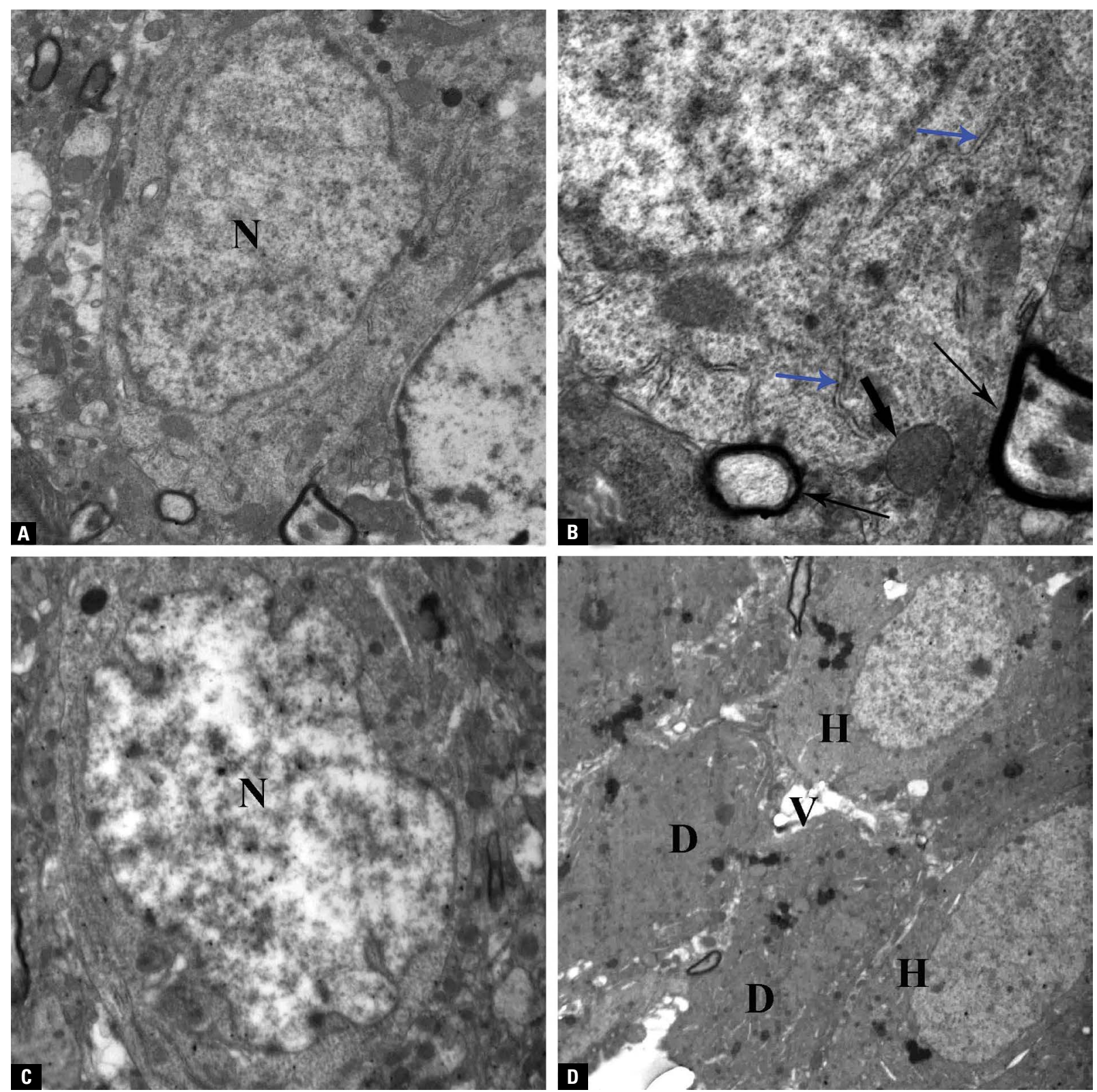

Figure 10. Transmission electron microscopic micrographs of neurocytes of the cyclophosphamide plus nano-selenium group; A. A cell with electro-lucent nucleus $(\mathrm{N})$ with a nearly regular outline and dispersed chromatin; B. A higher magnification of panel A showing healthy mitochondria (thick arrow), nearly normal rough E (blue arrow), and intact neurolemmal sheaths (thin arrow); C. A cell with electro-lucent nucleus $(\mathrm{N})$ with irregular outline; $\mathbf{D}$. Healthy cells $(\mathrm{H})$ and damaged cells $(\mathrm{D})$ with deeply stained nuclei and cytoplasmic vacuolation (V) $(A, C: \times 2500, B: \times 6000, D: \times 1500)$.

as compared to the $\mathrm{CPH}$ group. These ameliorating results induced by nano-Se were in harmony with the previous studies insuring the ameliorating effect of nano-Se on the different tissues against the tissue deleterious effect of cyclophosphamide and the other injurious factors. In this context, Bhattacharjee et al., 2014 [7] reported that nano-Se alleviated degenerative changes in the liver induced by $\mathrm{CPH}$. Moreover, Hamza et al., 2020 [17] reported that nano-Se could protect also against the hepatocellular damage induced by acrylamide. Additionally, Dkhil et al., 2016 [13] stated that nano-Se prevented and minimised diabetes-induced spermatogenic cell loss in diabetic rats. Similarly, Abdel-Hakeem et al., 2020 [1] reported that nano-Se could mitigate the degeneration, necrosis, and inflammation of pancreatic acini and Langerhans cells caused by acute pancreatitis.

The protective effect of nano-Se on the hippocampus and the other tissues may be due to its antioxidant power against the oxidant damaging effect of 
$\mathrm{CPH}$ as stated by the previous studies. Akomolafe et al., 2020 [2] postulated that CPH has a pro-oxidant character and its administration is associated with induction of oxidative stress by the generation of free radicals. Moreover, Valko et al., 2006 [52] reported that higher levels of malondialdehyde were noted in the brain of $\mathrm{CPH}$ treated mice. Malondialdehyde is an outcome of lipid peroxidation and has been recorded to cause neuronal damage [52]. On the other hand, nano-Se significantly inhibited CPH induced free radicals formation which may be due to its antioxidant property [7]. Nano Se played important roles in the enhancement of the antioxidant defence system and scavenging free radicals by increasing activities of both and glutathione S-transferase and glutathione peroxidase $[20,40,58]$.

In the present study, the thickness of the neurocyte cell layers (pyramidal and granule layers) was significantly reduced in the group treated with $\mathrm{CPH}$. This reduction occurred due to the decrease in the neurocyte population owing to the cellular damage (necrosis and/or apoptosis). Additionally, the reduction in the population of cells may be also due to the inhibition of hippocampal neurogenesis by $\mathrm{CPH}$ that was mentioned recently in numerous studies. The reduction in hippocampal neurogenesis by $\mathrm{CPH}$ could affect the hippocampal related cognitive functions and memory $[12,56]$. Nano-Se, in the present study, prevented the decrease in the thickness of neurocyte cell layers in the group treated with CPH plus nano-Se. This may be due to the prevention of cellular degeneration, necrosis, and apoptosis by nano-Se. The positive impact of nano-Se on neurogenesis may be also assumed which could be an additional cause of increased neurocyte cell layers thickness.

Caspase- 3 has been known as an essential therapeutic target in neurodegeneration owing to its involvement in neuroinflammation and apoptosis [21]. Immunohistochemical examination and morphometric analysis, in the current study, revealed that $\mathrm{CPH}$ injection significantly increased the area percentage of caspase- 3 reaction and the Al which reflected the increase in the number of cells showing positive reactions to caspase-3 (an apoptosis marker). This result was in line with the observations of Shaibah et al., 2016 [44] who reported that immunohistochemical section of rats injected with CPH showed a large number of apoptotic neurons with a positive reaction for p53 (an apoptosis marker) and a less positive reaction for Bcl2 (anti-apoptotic marker).
The immunohistochemical results also revealed that nano-Se reduced the area percentage of caspase- 3 reaction and the $\mathrm{Al}$ in the group exposed to $\mathrm{CPH}$ plus nano-Se. Our results were in harmony with that of Wang et al., 2019 [53] who studied the effect of nano-Se on cultured pancreatic cells. They stated that nano-Se completely inhibited the activation of caspase- $3,-8$, and -9 and consequently, suppressing apoptosis. On the contrary Huang et al., 2010 [18] proved that nano-Se provoked initiation of apoptosis through destabilization of the membrane potential of mitochondria and raised the expression of many pro-apoptotic caspases. These differences in results may due to the variations in doses and sizes of nano-Se utilised. As for nano-Se to produce apoptosis, it should reside within the cell at high concentrations. Moreover, the diversity in cell type upon which nano-Se acts, the variations in cellular redox status, and different durations of administration may be other causes [22].

Glial fibrillary acidic protein is a cellular protein that is found in various cell types of the brain particularly astrocytes [48]. GFAP is known to be essential for changing astrocyte shape and mobility by increasing the structural stability of the processes of astrocytes [29]. GFAP is also known as a specific marker for the maturity of astrocytes [14]. It was found that injury of the brain, whether because of chemical agents, diseases, or trauma led to astrogliosis. In astrogliosis, rapid synthesis of GFAP occurs and is detected by immunostaining with GFAP antibodies [26]. In the current study, CPH triggered the activation of astrocytes that was manifested in the form of increased expression of GFAP. This might be a compensatory mechanism for neuronal damage. Moreover, nano-Se significantly reduced the expression of GFAP which indicated that nano-Se could inhibit CPH induced neuronal damage and its concomitant astrogliosis.

So far, there was very limited data in the previous studies about the effect $\mathrm{CPH}$ on the ultrastructure of the hippocampus in adult rats. By TEM, the results of the present study revealed that $\mathrm{CPH}$ produced mild dilation of rough endoplasmic reticulum, mitochondrial cristeolysis, disrupted neurolemmal sheaths of nerve fibres, neuronal degeneration, and necrosis which was greatly reversed by nano-Se co-treatment. Our observations were in harmony with the developmental study of Xiao et al., 2007 [54] who reported that CPH decreased the growth and viability of neurons, destroyed 
nuclear DNA, and provoked apoptotic morphological alterations in rat embryos. CPH may induce neuroinflammation and neurodegeneration due to enhancing nitric oxide synthesis and increasing arginase activity. Experimental studies have revealed that elevated arginase activity and changes in nitric oxide levels may contribute to neurodegeneration [11, 38]. Additionally, Mohammed and Safwat, 2013 [33] reported that the administration of nano-Se significantly decreased the nitric oxide concentration in brain tissue. So, the reduction in the nitric oxide level caused by nano-Se may be one of the causes of its neuroprotective effects.

\section{CONCLUSIONS}

Cyclophosphamide injection in rats triggered cellular degeneration, necrosis, and apoptosis of hippocampal neurocytes. Moreover, it caused mild dilation of rough endoplasmic reticulum, mitochondrial cristeolysis, and disrupted neurolemmal sheaths of nerve fibres at the ultrastructural level. Nano-Se co-treatment mitigated these deleterious changes induced by cyclophosphamide. So, nano-Se supplementation to the diet of patients treated with $\mathrm{CPH}$ may be useful. Further studies are required to elucidate the mechanism of action nano selenium as a protective factor against chemotherapeutic drugs as cyclophosphamide.

\section{Funding}

This work was in part financially supported in the framework of the project "Biological production of nano-selenium spheres and its application in livestock production" by the National Strategy for Genetic Engineering and Biotechnology, Academy of Scientific Research and Technology, Egypt.

\section{Conflict of interest: None declared}

\section{REFERENCES}

1. Abdel-Hakeem EA, Abdel-Hamid HA, Abdel Hafez SM. The possible protective effect of Nano-Selenium on the endocrine and exocrine pancreatic functions in a rat model of acute pancreatitis. J Trace Elem Med Biol. 2020; 60: 126480, doi: 10.1016/j.jtemb.2020.126480, indexed in Pubmed: 32146341.

2. Akomolafe SF, Olasehinde TA, Oyeleye SI, et al. Curcumin administration mitigates cyclophosphamide-induced oxidative damage and restores alteration of enzymes associated with cognitive function in rats' brain. Neurotox Res. 2020; 38(1): 199-210, doi: 10.1007/s12640-020-00205-0, indexed in Pubmed: 32405958.
3. Arumugam N, Sivakumar V, Thanislass J, et al. Effects of acrolein on rat liver antioxidant defense system. Indian J Exp Biol. 1997; 35(12): 1373-1374, indexed in Pubmed: 9567773.

4. Bancroft J, Layton C, Suvarna S.K. Bancroft's Theory and Practice of Histological Techniques: Expert Consult: Online and Print, 7e; 2012.

5. Bancroft J, Stonard J. Classical histochemical methods. Bancroft's Theory and Practice of Histological Techniques. 2013: 563-575, doi: 10.1016/b978-0-7020-4226-3.00025-1.

6. Barton D, Loprinzi C. Novel approaches to preventing chemotherapy-induced cognitive dysfunction in breast cancer: the art of the possible. Clin Breast Cancer. 2002; 3 Suppl 3: S121-S127, doi: 10.3816/cbc.2002.s.023, indexed in Pubmed: 12533273.

7. Bhattacharjee A, Basu A, Ghosh P, et al. Protective effect of Selenium nanoparticle against cyclophosphamide induced hepatotoxicity and genotoxicity in Swiss albino mice. J Biomater Appl. 2014; 29(2): 303-317, doi: $10.1177 / 0885328214523323$, indexed in Pubmed: 24522241.

8. Bohnenstengel F, Friedel G, Ritter CA, et al. Variability of cyclophosphamide uptake into human bronchial carcinoma: consequences for local bioactivation. Cancer Chemother Pharmacol. 2000; 45(1): 63-68, doi: 10.1007/PL00006745, indexed in Pubmed: 10647504.

9. Boostani A, Sadeghi AA, Mousavi SN, et al. Effects of organic, inorganic, and nano-Se on growth performance, antioxidant capacity, cellular and humoral immune responses in broiler chickens exposed to oxidative stress. Livestock Sci. 2015; 178: 330-336, doi: 10.1016/j.livsci.2015.05.004.

10. Cai SJ, Wu CX, Gong LM, et al. Effects of nano-selenium on performance, meat quality, immune function, oxidation resistance, and tissue selenium content in broilers. Poult Sci. 2012; 91(10): 2532-2539, doi: 10.3382/ps.201202160, indexed in Pubmed: 22991539.

11. Caldwell RB, Toque HA, Narayanan SP, et al. Arginase: an old enzyme with new tricks. Trends Pharmacol Sci. 2015; 36(6): 395-405, doi: 10.1016/j.tips.2015.03.006, indexed in Pubmed: 25930708.

12. Christie LA, Acharya MM, Parihar VK, et al. Impaired cognitive function and hippocampal neurogenesis following cancer chemotherapy. Clin Cancer Res. 2012; 18(7): 1954-1965, doi: 10.1158/1078-0432.CCR-11-2000, indexed in Pubmed: 22338017.

13. Dkhil MA, Zrieq R, Al-Quraishy $\mathrm{S}$, et al. Selenium nanoparticles attenuate oxidative stress and testicular damage in streptozotocin-induced diabetic rats. Molecules. 2016; 21(11), doi: 10.3390/molecules21111517, indexed in Pubmed: 27869771.

14. Eng LF, Ghirnikar RS, Lee YL. Glial fibrillary acidic protein: GFAP-thirty-one years (1969-2000). Neurochem Res. 2000; 25(9-10): 1439-1451, doi: 10.1023/a:1007677003387, indexed in Pubmed: 11059815.

15. Goud KG, Veldurthi NK, Vithal M, et al. Characterization and evaluation of biological and photocatalytic activities of selenium nanoparticles synthesized using yeast fermented broth. Applied Nanomedicine. Published online. 2016. 
16. Hamoud A. Possible role of selenium nano-particles on gentamicin-induced toxicity in rat testis: morphological and morphometric study. Egypt J Histol. 2019; 0(0): 0-0, doi: 10.21608/ejh.2019.9926.1093.

17. Hamza R, EL-Megharbel S, Altalhi T, et al. Hypolipidemic and hepatoprotective synergistic effects of selenium nanoparticles and vitamin. E against acrylamide-induced hepatic alterations in male albino mice. Applied Organometallic Chemistry. 2020; 34(3), doi: 10.1002/aoc.5458.

18. Huang G, Zhang Y, Zhang Q, et al. Vacuolization and apoptosis induced by nano-selenium in HeLa cell line. Science China Chemistry. 2010; 53(11): 2272-2278, doi: 10.1007/ s11426-010-4116-7.

19. Kannan N, Subbalaxmi S. Biogenesis of nanoparticles: a current perspective. Reviews on Advanced Materials Science. Published online. 2011.

20. Khalaf AA, Ahmed W, Moselhy WA, et al. Protective effects of selenium and nano-selenium on bisphenol-induced reproductive toxicity in male rats. Hum Exp Toxicol. 2019; 38(4): 398-408, doi: 10.1177/0960327118816134, indexed in Pubmed: 30526071.

21. Khan S, Ahmad K, Alshammari EMA, et al. Implication of caspase-3 as a common therapeutic target for multineurodegenerative disorders and its inhibition using nonpeptidyl natural compounds. Biomed Res Int. 2015; 2015: 379817, doi: $10.1155 / 2015 / 379817$, indexed in Pubmed: 26064904.

22. Khurana A, Tekula S, Saifi MA, et al. Therapeutic applications of selenium nanoparticles. Biomed Pharmacother. 2019; 111: 802-812, doi: 10.1016/j.biopha.2018.12.146, indexed in Pubmed: 30616079.

23. Kitamura $Y$, Kanemoto $E$, Sugimoto $M$, et al. Influence of nicotine on doxorubicin and cyclophosphamide combination treatment-induced spatial cognitive impairment and anxiety-like behavior in rats. Naunyn Schmiedebergs Arch Pharmacol. 2017; 390(4): 369-378, doi: 10.1007/s00210016-1338-z, indexed in Pubmed: 28064347.

24. Kumar A, Prasad KS. Biogenic selenium nanoparticles for their therapeutic application. Asian J Pharmaceut Clin Res. 2019: 4-9, doi: 10.22159/ajpcr.2020.v13i1.35599.

25. Lal Bhatia A, Manda K, Patni S, et al. Prophylactic action of linseed (Linum usitatissimum) oil against cyclophosphamide-induced oxidative stress in mouse brain. J Med Food. 2006; 9(2): 261-264, doi: 10.1089/jmf.2006.9.261, indexed in Pubmed: 16822213.

26. Li DRi, Ishikawa T, Zhao D, et al. Histopathological changes of the hippocampus neurons in brain injury. Histol Histopathol. 2009; 24(9): 1113-1120, doi: 10.14670/ HH-24.1113, indexed in Pubmed: 19609858.

27. Liang XJ, Chen $\mathrm{C}$, Zhao Y, et al. Circumventing tumor resistance to chemotherapy by nanotechnology. Methods Mol Biol. 2010; 596: 467-488, doi: 10.1007/978-1-60761416-6_21, indexed in Pubmed: 19949937.

28. Ludeman SM. The chemistry of the metabolites of cyclophosphamide. Curr Pharm Des. 1999; 5(8): 627-643, indexed in Pubmed: 10469895.

29. Lumpkins KM, Bochicchio GV, Keledjian K, et al. Glial fibrillary acidic protein is highly correlated with brain injury. J Trauma. 2008; 65(4): 778-782, doi: 10.1097/TA.0b013e318185db2d, indexed in Pubmed: 18849790.
30. Lyons L, Elbeltagy M, Bennett G, et al. The effects of cyclophosphamide on hippocampal cell proliferation and spatial working memory in rat. PLoS One. 2011; 6(6): e21445, doi: 10.1371/ journal.pone.0021445, indexed in Pubmed: 21731752.

31. Martin PM, O'Callaghan JP. A direct comparison of GFAP immunocytochemistry and GFAP concentration in various regions of ethanol-fixed rat and mouse brain. J Neurosci Methods. 1995; 58(1-2): 181-192, doi: 10.1016/01650270(94)00175-g, indexed in Pubmed: 7475226.

32. Modica-Napolitano JS, Singh KK. Mitochondria as targets for detection and treatment of cancer. Expert Rev Mol Med. 2002; 4(9): 1-19, doi: 10.1017/S1462399402004453, indexed in Pubmed: 14987393.

33. Mohammed ET, Safwat GM. Assessment of the ameliorative role of selenium nanoparticles on the oxidative stress of acetaminophen in some tissues of male albino rats. Beni-Suef University J Basic Applied Sci. 2013; 2(2): 80-85, doi: 10.1016/j.bjbas.2013.01.003.

34. Morcos M. Histological and immunohistochemical study on the protective effects of cetrorelix against chemotherapy-induced ovarian damage. Egypt J Histol. 2012; 35(3): 587-597, doi: 10.1097/01.ehx.0000418132.61834.19.

35. Nagy G, Pinczes G, Pinter G, et al. In situ electron microscopy of lactomicroselenium particles in probiotic bacteria. Int J Mol Sci. 2016; 17(7), doi: 10.3390/ijms17071047, indexed in Pubmed: 27376279.

36. Narayanan KB, Sakthivel N. Biological synthesis of metal nanoparticles by microbes. Adv Colloid Interface Sci. 2010; 156(1-2): 1-13, doi: 10.1016/j.cis.2010.02.001, indexed in Pubmed: 20181326.

37. Oboh G, Ogunruku OO. Cyclophosphamide-induced oxidative stress in brain: protective effect of hot short pepper (Capsicum frutescens L. var. abbreviatum). Exp Toxicol Pathol. 2010; 62(3): 227-233, doi: 10.1016/j. etp.2009.03.011, indexed in Pubmed: 19447589.

38. Olasehinde TA, Olaniran AO, Okoh Al. Neuroprotective effects of some seaweeds against $Z n$ - induced neuronal damage in HT-22 cells via modulation of redox imbalance, inhibition of apoptosis and acetylcholinesterase activity. Metab Brain Dis. 2019; 34(6): 1615-1627, doi: 10.1007/ s11011-019-00469-2, indexed in Pubmed: 31346859.

39. Oraby HAS, Hassan AAM, Af N, et al. Effect of cyclophosphamide on transcription of SOD1 mRNA and GPX1 mRNA in mice liver and brain tissues. Published online. 2010: 1736-1742.

40. Peng D, Zhang J, Liu Q, et al. Size effect of elemental selenium nanoparticles (Nano-Se) at supranutritional levels on selenium accumulation and glutathione S-transferase activity. J Inorg Biochem. 2007; 101(10): 1457-1463, doi: 10.1016/j. jinorgbio.2007.06.021, indexed in Pubmed: 17664013.

41. Prokisch J, Zommara MA. Process for producing elemental selenium nanospheres. 2010;(20100189634). http://www. freepatentsonline.com/y2010/0189634.html.

42. Salem M, Altayeb Z. Light and Electron Microscopic Study on the Possible Protective Effect of Nigella Sativa Oil on Cisplatin Hepatotoxicity in Albino Rats. Egypt J Histol. 2017; 40(1): 68-79, doi: 10.21608/ejh.2017.3698.

43. Seigers $R$, Loos $M$, Van Tellingen $O$, et al. Cognitive impact of cytotoxic agents in mice. Psychopharmacology (Berl). 2015; 232(1): 17-37, doi: 10.1007/s00213-014-3636-9, indexed in Pubmed: 24894481. 
44. Shaibah HS, Elsify AEK, Medhat TM, et al. Histopathological and immunohistochemical study of the protective effect of triptorelin on the neurocytes of the hippocampus and the cerebral cortex of male albino rats after short-term exposure to cyclophosphamide. J Microsc Ultrastruct. 2016; 4(3): 123-132, doi: 10.1016/j.jmau.2015.12.002, indexed in Pubmed: 30023218.

45. Shakibaie M, Forootanfar H, Golkari Y, et al. Anti-biofilm activity of biogenic selenium nanoparticles and selenium dioxide against clinical isolates of Staphylococcus aureus, Pseudomonas aeruginosa, and Proteus mirabilis. J Trace Elem Med Biol. 2015; 29: 235-241, doi: 10.1016/j. jtemb.2014.07.020, indexed in Pubmed: 25175509.

46. Sheiha AM, Abdelnour SA, Abd El-Hack ME, et al. Effects of dietary biological or chemical-synthesized nano-selenium supplementation on growing rabbits exposed to thermal stress. Animals (Basel). 2020; 10(3), doi: 10.3390/ ani10030430, indexed in Pubmed: 32143370.

47. Skalickova S, Milosavljevic V, Cihalova K, et al. Selenium nanoparticles as a nutritional supplement. Nutrition. 2017; 33: 83-90, doi: 10.1016/j.nut.2016.05.001, indexed in Pubmed: 27356860.

48. Sobaniec-Lotowska ME. Ultrastructure of Purkinje cell perikarya and their dendritic processes in the rat cerebellar cortex in experimental encephalopathy induced by chronic application of valproate. Int J Exp Pathol. 2001; 82(6): 337-348, doi: 10.1046/j.1365-2613.2001.00206.x, indexed in Pubmed: 11846840.

49. Stankiewicz A, Skrzydlewska E, Makieła M. Effects of amifostine on liver oxidative stress caused by cyclophosphamide administration to rats. Drug Metabol Drug Interact. 2002; 19(2): 67-82, doi: 10.1515/dmdi.2002.19.2.67, indexed in Pubmed: 12751907.

50. Subramaniam S, Subramaniam S, Shyamala Devi CS. Erythrocyte antioxidant enzyme activity in CMF treated breast cancer patients. Cancer Biochem Biophys. 1994; 14(3): 177-182, indexed in Pubmed: 7728738.

51. Ueno M, Katayama Ki, Yamauchi H, et al. Cell cycle progression is required for nuclear migration of neural progenitor cells. Brain Res. 2006; 1088(1): 57-67, doi: 10.1016/j. brainres.2006.03.042, indexed in Pubmed: 16650835.

52. Valko M, Leibfritz D, Moncol J, et al. Free radicals and antioxidants in normal physiological functions and human disease. Int J Biochem Cell Biol. 2007; 39(1): 44-84, doi: 10.1016/j. biocel.2006.07.001, indexed in Pubmed: 16978905.

53. Wang L, Li C, Huang Q, et al. Biofunctionalization of selenium nanoparticles with a polysaccharide from Rosa roxburghii fruit and their protective effect against HO-induced apoptosis in INS-1 cells. Food Funct. 2019; 10(2): 539-553, doi: 10.1039/c8fo01958d, indexed in Pubmed: 30662993.

54. Xiao R, Yu HL, Zhao HF, et al. Developmental neurotoxicity role of cyclophosphamide on post-neural tube closure of rodents in vitro and in vivo. Int J Dev Neurosci. 2007; 25(8): 531-537, doi: 10.1016/j.ijdevneu.2007.09.012, indexed in Pubmed: 18022788.

55. Xu C, Shu WQ, Qiu ZQ, et al. Protective effects of green tea polyphenols against subacute hepatotoxicity induced by microcystin-LR in mice. Environ Toxicol Pharmacol. 2007; 24(2): 140-148, doi: 10.1016/j.etap.2007.04.004, indexed in Pubmed: 21783802.

56. Yang M, Kim JS, Song MS, et al. Cyclophosphamide impairs hippocampus-dependent learning and memory in adult mice: Possible involvement of hippocampal neurogenesis in chemotherapy-induced memory deficits. Neurobiol Learn Mem. 2010; 93(4): 487-494, doi: 10.1016/j. nlm.2010.01.006, indexed in Pubmed: 20109567.

57. Yu Bo, Zhang Y, Zheng W, et al. Positive surface charge enhances selective cellular uptake and anticancer efficacy of selenium nanoparticles. Inorg Chem. 2012; 51(16): 8956-8963, doi: $10.1021 / \mathrm{ic301050v}$, indexed in Pubmed: 22873404.

58. Zhang J, Zhang SY, Xu JJ, et al. new method for the synthesis of selenium nanoparticles and the application to construction of $\mathrm{H} 2 \mathrm{O} 2$ biosensor. Chinese Chemical Letters. Published online. 2004.

59. Zhao CY, Cheng R, Yang Z, et al. Nanotechnology for cancer therapy based on chemotherapy. Molecules. 2018; 23(4), doi: 10.3390/molecules23040826, indexed in Pubmed: 29617302. 